\title{
Modelo Biopsicosocial: De la teoría a la clínica
}

\section{Biopsychosocial model: From theory to clinical}

\author{
Juan Luis Arrieta-Villarreal ${ }^{a}$ Rebeca Guzmán-Saldaña ${ }^{b}$
}

\begin{abstract}
:
The Biopsychosocial model was proposed by George L. Engel in 1977 as a criticism of the predominant medical model at the time, which limited the understanding of physical and psychological conditions and disorders associated to the presence of organic factors, such as injuries and abnormalities. Engel's model has had a great boom in the understanding of the health-disease process of individuals, and more recently in the clinical application, setting guidelines for the care provided by different health professionals (doctors, psychologists, dentists, nurses, etc.). In addition, Engel's model has laid the fundaments for the development of factors involved in government policies on health. The realization of this mental map responds to the need to create support material for the understanding of the Biopsychosocial model. It is important to mention that this mind map is an introductory material to this model, which seeks to make known their main characteristic, clinical application, and some of the criticisms it makes to the classic medical model of health-disease.
\end{abstract}

Keywords:

biopsychosocial model; health-disease process; Engel's model

Resumen:

El modelo Biopsicosocial fue propuesto por George L. Engel en 1977 como una crítica ante el modelo médico predominante en la época, el cual limitaba la comprensión de las afecciones y trastornos físicos y psicológicos asociados con la presencia de factores orgánicos, tales como lesiones y anomalías. El modelo de Engel ha tenido un gran auge en el entendimiento del proceso saludenfermedad de los individuos, y más recientemente en la aplicación clínica, marcando pautas para la atención brindada por los distintos profesionales de la salud (médicos, psicólogos, odontólogos, enfermeros, etc.). Así mismo, ha sentado las bases en el desarrollo de factores implicados en las políticas gubernamentales en materia de salud. La realización de este mapa mental responde a la necesidad de crear material de apoyo para la comprensión del modelo Biopsicosocial. Es importante mencionar que este mapa mental es un material introductorio a dicho modelo, que busca dar a conocer sus principales características, su aplicación clínica, y algunas críticas que realiza al modelo médico clásico de salud-enfermedad.

Palabras Clave:

modelo biopsicosocial; proceso salud-enfermedad; modelo de Engel

\footnotetext{
a Autor de Correspondencia, Universidad Autónoma del Estado de Hidalgo, Email: ar295077@uaeh.edu.mx

b Universidad Autónoma del Estado de Hidalgo, https://orcid.org/0000-0003-0877-4871, Email: rguzman@uaeh.edu.mx
} 


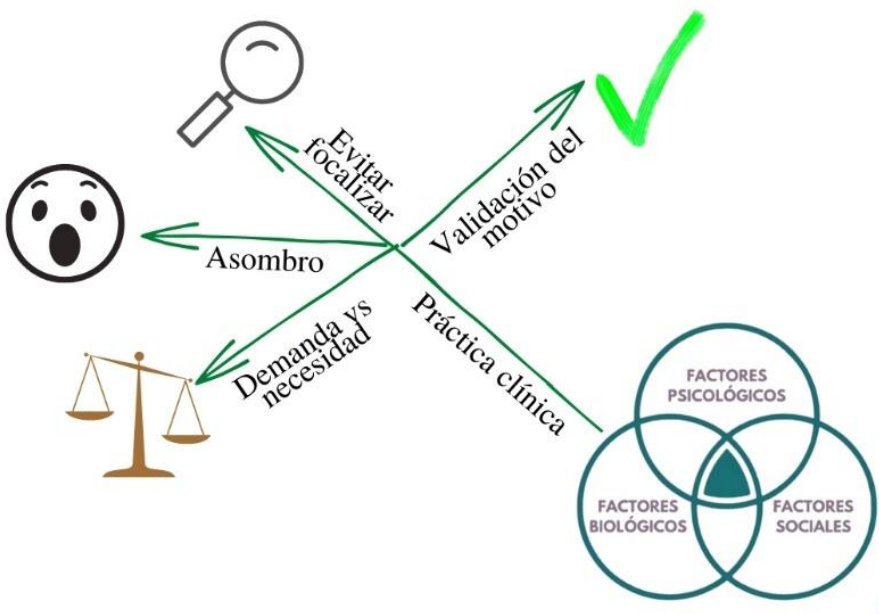

MODELO BIOPSICOSOCIA

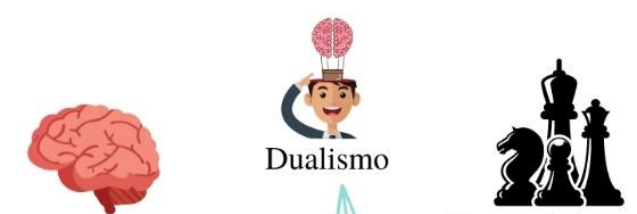

Biologismo

Determinismo
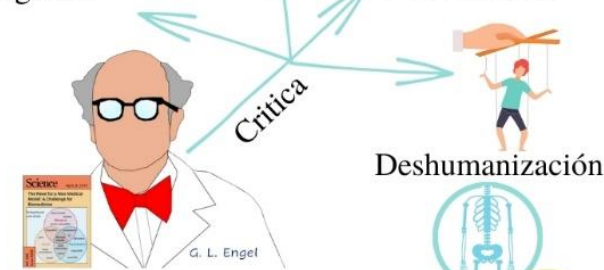

Deshumanización
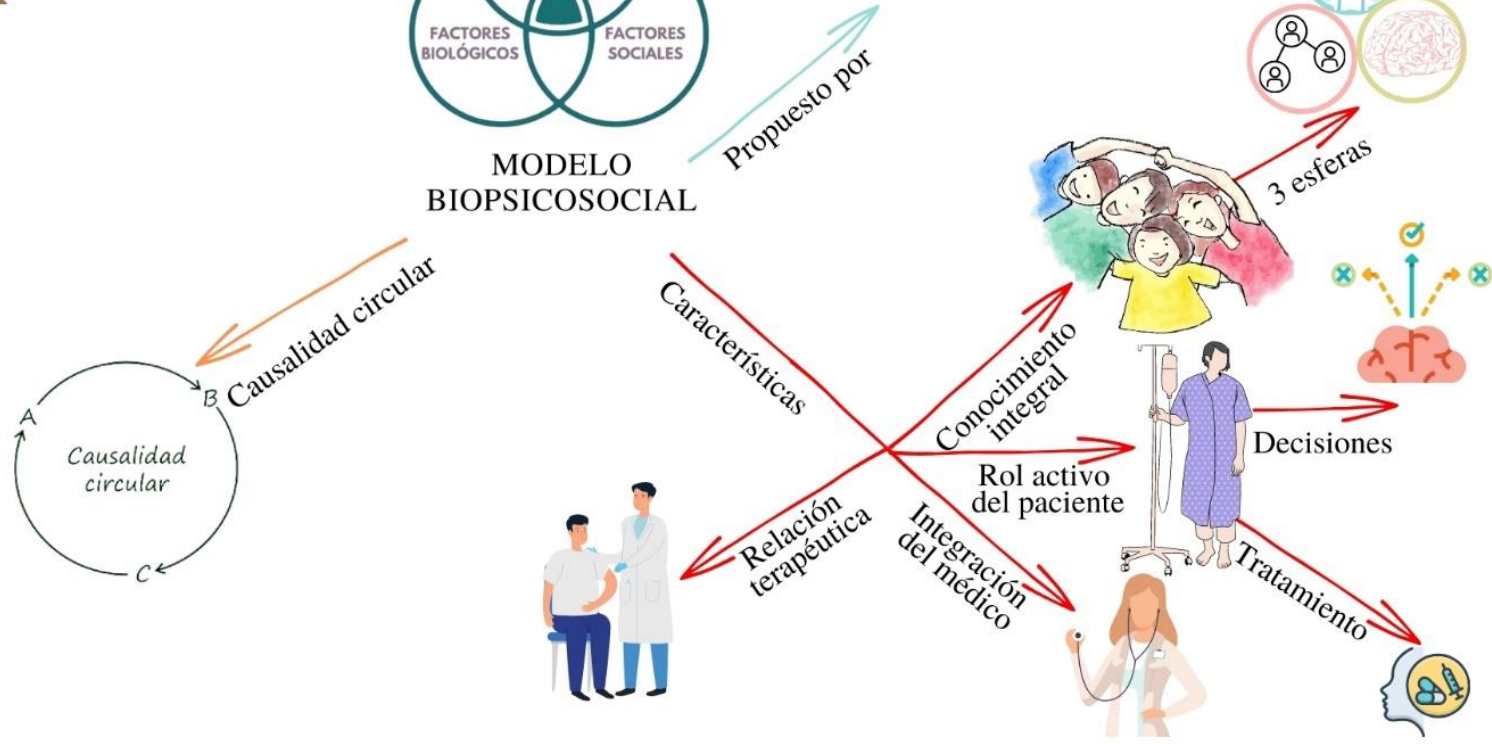

Referencias

[1] Borrell i Carrió, F. (2002). El Modelo Biopsicosocial en Evolución. Medicina Clínica, 119(5), 175-179.

[2] Tizón García, J. (2007). A propósito del modelo biopsicosocial, 28 años después: epistemología, política, emociones y contratransferencia. Atención Primaria, 39(2), 93-97. 